\title{
Hvordan sætter jeg min OJS-server op så der automatisk tildeles DOI med direkte eksport til CrossRef?
}

\section{Af Jesper Boserup Thestrup}

Denne artikel er tænkt som en hjælp til administratorer, der skal sætte DOI op på en OJS-server version 2.4.6. for de tidsskifter, der udgives på serveren. Hvert enkelt tidsskrift skal sættes op enkeltvis. For at kunne følge anvisningerne skal man have en konto (brugernavn og password) ved Crossref. Når du har fulgt disse anvisninger vil der dukke et DOI op på de enkelte artiklers landing page.

\section{Redaktionelt forord til "Temanummer om DOI og OJS" \\ Jesper Boserup Thestrup, Niels Erik Frederiksen}

\section{Resumé}

Forord

Nøgleord

DOI; OJS

Fuld tekst:

PDF

\section{Referencer}

Thestrup, J., Frederiksen, N.E. (2014). DOI, CrossRef og OJS-servere. OJS på Dansk, 5(4) doi: http://dx.doi.ora/10.7146/ojssb.v6i5.20601

DOI: http://dx.doi.ora/10.7146/ojssb.v6i5.20601

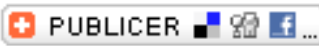

Hosted by The State and University Library - Aarhus

Illustration 1: DOI tilknyttet en artikel 


\section{1: Hvor skal jeg ændre i opsætningen?}

Du skal gøre noget to steder i opsætningen af hvert tidsskrift.

- DOI plugin.

CrossRef Eksport/Registrerings-Plug-in

\section{2: Opsætning af DOI Plugin}

Du skal logge ind som tidsskriftschef. Der ser du listen over administrationssider og klikker" System-plugins". Der dukker en liste over forskellige typer plugins op. Du klikker på "Public Identificer plug-ins". Derefter dukker der en side op med et DOI plugin. Der klikker du først på "Aktiver" og derefter "Indstillinger".

Først skal du angive hvilke elementer du vil have OJS til at tildele DOI. Vi arbejder udelukkende med "Artikler". Derefter skal du indtaste det Prefix (kundenummer) som identificerer din server. Derefter går du videre ned på siden.

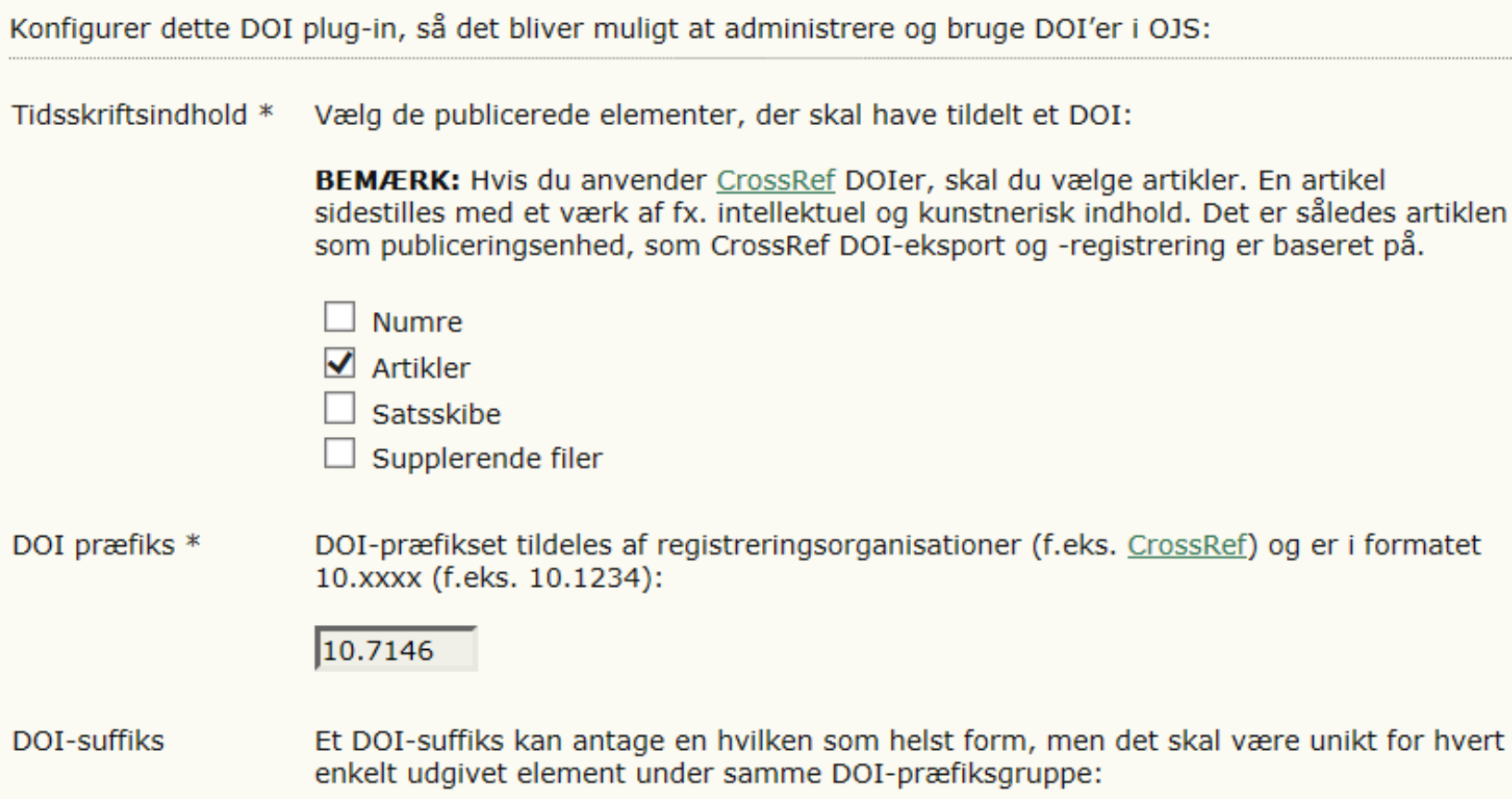

DOI præfiks * DOI-præfikset tildeles af registreringsorganisationer (f.eks. CrossRef) og er i formatet 10.xxxx (f.eks. 10.1234):

10.7146

DOI-suffiks Et DOI-suffiks kan antage en hvilken som helst form, men det skal være unikt for hvert enkelt udgivet element under samme DOI-præfiksgruppe:

Illustration 2: Opsætning ad DOI plugin 1

OJS giver dig mulighed for at definere den eksakte måde som dine DOI'er skal se ud. Vi vælger standardformaterne til artikler. Man skal være meget præcis i den måde man opbygger sine DOI for at undgå dubletter. Samtidigt sikrer, vi at man let kan skelne mellem de forskellige tidsskrifter. 
Klik nu på "Tildel nye DOI" og "Gem".

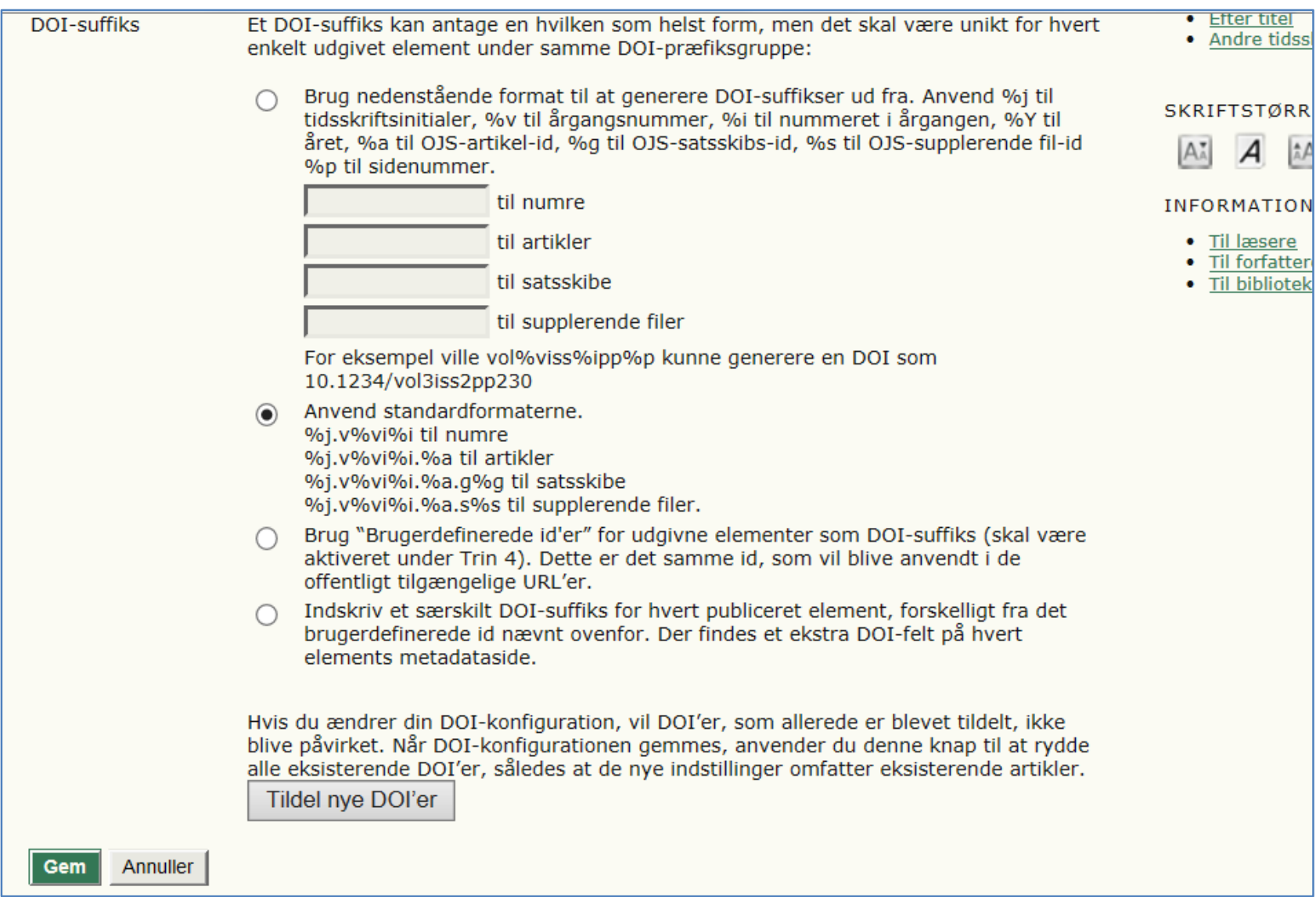

Illustration 2: Opsætning ad DOI plugin 2 


\section{3: Eksport af DOl'er til CrossRef.}

Du skal sikre, at dine data bliver eksporterede til CrossRef og DOI.org. Det kræver at du sætter eksport plugin'en op. Du skal logge ind som tidsskriftschef. Derefter skal du under listen "Administrationssider" klikke på "Importer/Eksporter data". Der skal du igen klikke på "Crossref Eksport/Registrerings-plug-in".

Du skal først aktivere plug-in'en. Klik på "konfigurer Crossref eksport/registerings plug-in'en her". Der vil du blive bedt om at opgive dit navn, din e-mail og det brugernavn og password du har fået af CrossRef.

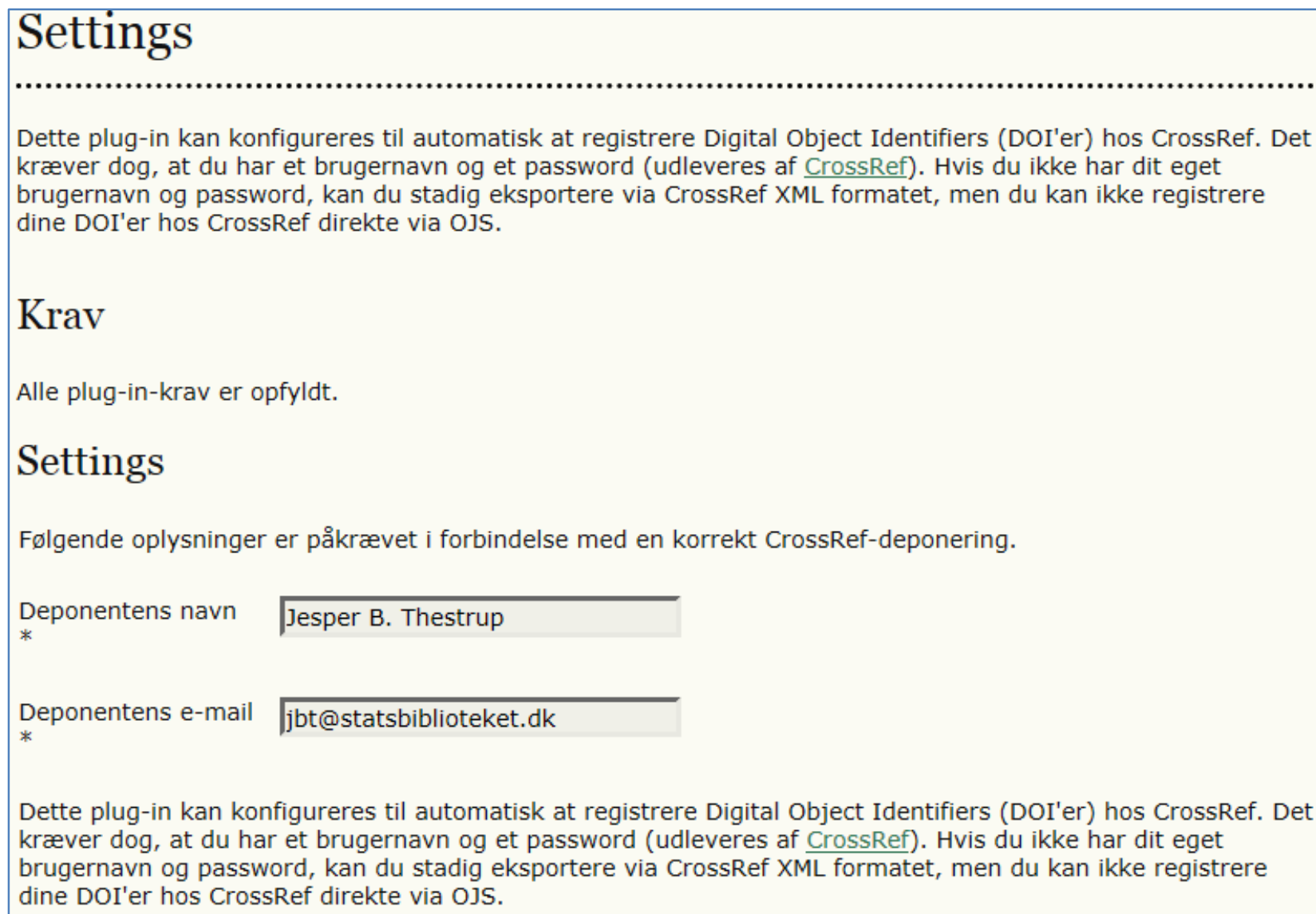

\section{Krav}

Alle plug-in-krav er opfyldt.

\section{Settings}

Følgende oplysninger er påkrævet i forbindelse med en korrekt CrossRef-deponering.

Deponentens navn Jesper B. Thestrup

*

Deponentens e-mail jbt@statsbiblioteket.dk

Dette plug-in kan konfigureres til automatisk at registrere Digital Object Identifiers (DOI'er) hos CrossRef. Det kræver dog, at du har et brugernavn og et password (udleveres af CrossRef). Hvis du ikke har dit eget brugernavn og password, kan du stadig eksportere via CrossRef XML formatet, men du kan ikke registrere dine DOI'er hos CrossRef direkte via OJS.

Illustration 3: Aktivering af plugin 1 
Husk at markere "Registrer DOl'er automatisk".

Dette plug-in kan konfigureres til automatisk at registrere Digital Object Identifiers (DOI'er) hos CrossRef. Det kræver dog, at du har et brugernavn og et password (udleveres af CrossRef). Hvis du ikke har dit eget brugernavn og password, kan du stadig eksportere via CrossRef XML formatet, men du kan ikke registrere dine DOI'er hos CrossRef direkte via OJS.

Brugernavn

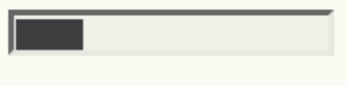

Password

\section{$\bullet \bullet \bullet \bullet \bullet \bullet$}

Please note that the password will be saved as plain text, i.e. not encrypted.

Registér DOI'er automatisk

$\checkmark$ OJS deponerer artikel-DOI'er automatisk i CrossRef samtidig med, at artiklerne bliver publiceret. Bemærk, at der kan gå kort tid mellem publicering og endelig færdigbehandling. Alle ikke-registrerede DOI'er kan fremfindes på listen over ikkeregistrerede artikler.

* Angiver obligatorisk felt

Illustration 4: Aktivering af plugin 2 
Når dette er gjort skal du eksportere dine artikler første gang. Det kan du gøre ved at eksportere alle artikler på en gang, alle numre på en gang eller ved at se listen over ikke registrerede artikler.

Her dukker der en liste over artikler op (eksemplet viser artikler der er sendt til CrossRef - teksten "Submitted" dukker op når processen er overstået). Udvælg de artikler du skal uploade. Det er en god ide ikke at tage alle artikler på en gang. Skulle der være flere fejl i dine metadata vil dette stroppe processen og der vil dukke en fejlmeddelelse op. Det er lettere at overskue, hvad der skal rettes, hvis man kun arbejder med et nummer eller en årgang ad gangen.

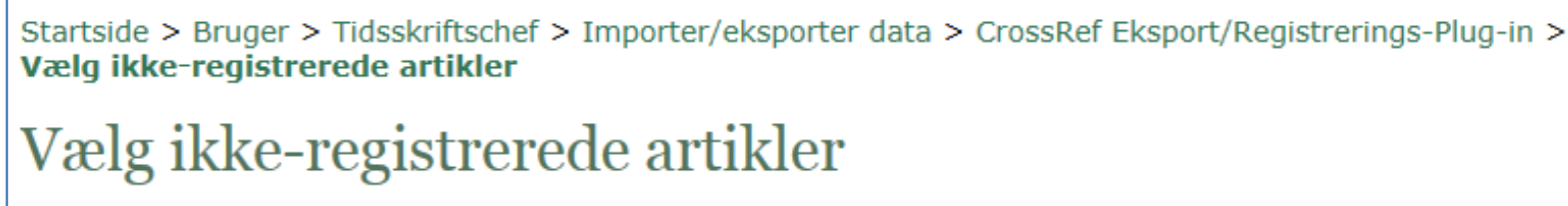

\begin{tabular}{|c|c|c|c|c|c|}
\hline & & NUMMER & TITEL & FORFATTERE & STATUS \\
\hline$\checkmark$ & Artikel & $\frac{\AA \text { ARG. 4, NR. } 3}{(2013)}$ & $\begin{array}{l}\text { SÅDAN SØGER MAN OM OPTAGELSE I } \\
\text { SCOPUS OG WEB OF SCIENCE }\end{array}$ & Anne Lyhne Høj & submitted \\
\hline$\checkmark$ & Artikel & $\frac{\frac{\AA}{\AA} \text { RG. 4, NR. } 3}{(2013)}$ & $\begin{array}{l}\text { OJS 2.4.2-NYHEDER (DANSK } \\
\text { BRUGERGRENSEFLADE) }\end{array}$ & $\begin{array}{l}\text { Niels Erik } \\
\text { Frederiksen }\end{array}$ & $\underline{\text { submitted }}$ \\
\hline$\checkmark$ & Artikel & $\frac{\frac{\AA}{\AA R G} .4, N R .3}{(2013)}$ & $\begin{array}{l}\text { OJS 2.4.2-NYHEDER (ENGELSK } \\
\text { BRUGERGRENSEFLADE) }\end{array}$ & $\begin{array}{l}\text { Niels Erik } \\
\text { Frederiksen }\end{array}$ & $\underline{\text { submitted }}$ \\
\hline$\checkmark$ & Artikel & $\frac{\frac{\AA}{\AA} \text { RG. 4, NR. } 3}{(2013)}$ & BECOMING AN EDITOR & $\begin{array}{l}\text { Niels Erik } \\
\text { Frederiksen/PKP- } \\
\text { OJS }\end{array}$ & submitted \\
\hline$\checkmark$ & Artikel & $\frac{\underline{\AA} \text { RG. 4, NR. } 3}{(2013)}$ & OJS FOR JOURNAL MANAGERS & $\begin{array}{l}\text { Niels Erik } \\
\text { Frederiksen/PKP- } \\
\text { OJS }\end{array}$ & submitted \\
\hline$\nabla$ & Artikel & $\frac{\underline{\AA R G} .4, N R .3}{(2013)}$ & OJS FOR EDITORS & $\begin{array}{l}\text { Niels Erik } \\
\text { Frederiksen/PKP- } \\
\text { OJS }\end{array}$ & $\underline{\text { submitted }}$ \\
\hline$\nabla$ & Artikel & $\frac{\AA \text { \&RG. 5, NR. } 4}{(2014)}$ & NYHEDER I OJS 2.4.5.0 & $\begin{array}{l}\text { Niels Erik } \\
\text { Frederiksen }\end{array}$ & $\underline{\text { submitted }}$ \\
\hline
\end{tabular}

Illustration 5: Valg af artikler.

Når du har udvalgt artiklerne klikker du "Register" nederst på Siden. OJS'en sender derefter data til CrossRef. Hvis processen virker, vil der efter et stykke tid stå Submitted. Artiklerne bliver søgbare hos DOI.org og Crossref ret hurtigt. Hvis du har klikket på automatisk registrering behøves du ikke gøre mere. 